\title{
MÁS ALLÁ DEL SALADERO. UNA MIRADA SOBRE LA PRODUCCIÓN DE CARNE SALADA EN EL RÍO DE LA PLATA DEL SIGLO XVIII
}

\author{
Beyond the saladero: a look at the production of salted meat in the Rio de la \\ Plata during the eighteenth century
}

\author{
Nicolás Biangardi* \\ http://orcid.org/0000-0002-1773-9552
}

\section{Resumen}

Este trabajo presenta un balance de los conocimientos actuales sobre la producción de carne salada en el Río de la Plata durante el siglo XVIII. Para ello, se comienza repasando aspectos relativos a la producción de carne salada, como los métodos utilizados y la abundancia del principal insumo de la actividad. Luego se analizan los dos segmentos que constituían el mercado de la carne salada. En este sentido, se plantea que las demandas derivadas del funcionamiento del complejo portuario podían ser abastecidas por la producción a pequeña escala de los establecimientos rurales, mientras que la exportación requirió un cambio de escala que derivó en la aparición de los saladeros. Por último, se indaga sobre las características de esos nuevos establecimientos argumentando que, en el siglo XVIII, éstos presentaron diferencias respecto a los que surgieron más adelante en el siglo XIX.

$$
<\text { Carne salada }><\text { Demanda }><\text { Saladeros }><\text { Río de la Plata }>
$$

\begin{abstract}
This paper provides an assessment of the current knowledge about the production of salted meat in the Río de la Plata during the eighteenth century. For this purpose, it begins with a review of aspects related to the production of salted meat, such as the methods used and the abundance of the main supplies for the activity. The two segments that constituted the market for salted meat are then analyzed. In this regard, it is suggested that the demands derived from the operation of the port complex could be met by the small-scale production of the rural establishments, while export required a change of scale that led to the appearance of the "saladeros" (salting rooms). Finally, it explores the characteristics of these new establishments, arguing that those that existed in the eighteenth century were different from those which emerged later in the nineteenth century.
\end{abstract}

$<$ Salted meat $><$ Demand $><$ Saladeros $><$ Río de la Plata $>$

Recibido: 24/09/2019

Aceptado: 23/03/2020

\footnotetext{
* Facultad de Humanidades y Ciencias de la Educación, Universidad Nacional de La Plata, Argentina, nicolas_biangardi@yahoo.com.ar
} 
Biangardi. Más allá del saladero. Una mirada sobre la producción de carne salada en el Río de la Plata del Siglo XVIII.

\section{Introducción}

La ganadería ocupa un lugar destacado en la historia y la cultura de las poblaciones que vivían en las extensas praderas rioplatenses. En un espacio donde siempre había más vacas que personas resulta lógico que surgieran actividades vinculadas a la conservación de la carne excedente. Antes de la aparición de la tecnología, que permitió la refrigeración, éstas se encontraban limitadas al secado y salado de las reses vacunas. Sin embargo, esa situación que plantearía un lugar aparentemente significativo, no se refleja en una atención destacada por parte de la historiografía dedicada a la historia agropecuaria rioplatense. Es probable que la razón se encuentre en las dificultades que presentan las fuentes para dar cuenta de la actividad. Debido, especialmente, a que los intentos de promocionarla por parte de los funcionarios de la corona derivaban en exenciones de impuestos. Las fuentes fiscales constituyen elementos fundamentales a la hora de reconstruir la historia económica rioplatense y, por ende, la exención de impuestos al desviar la atención de los recaudadores por este tipo de impuestos genera inconvenientes al momento de investigar.

De este modo, todavía se mantiene en pie la imagen tradicional que básicamente construyeron Montoya (1971; 1984) y Giberti (1986), quienes basaron sus trabajos en los datos que proporcionaban los informes de funcionarios o en los relatos de viajeros como Tadeo Haenke o Martín de Moussy. En general, esto se traduce en una atención centrada en los saladeros que deja de lado la producción a pequeña escala que tenía lugar en otros establecimientos productivos; y en una falta de precisión temporal que, en ocasiones, termina retrotrayendo al siglo XVIII situaciones que no se van a plantear hasta bien entrado el siglo XIX. En consecuencia, resulta necesario revisar estos presupuestos y repensar la cuestión a partir de la información nueva que surge de las actuales investigaciones sobre la economía rioplatense.

Por ende, este trabajo tiene como objetivo hacer un balance del conocimiento actual sobre la producción de carne salada durante el siglo XVIII, reflexionando sobre algunos tópicos que todavía se mantienen en pie y planteando algunos problemas que deben ser resueltos por futuras investigaciones. En las páginas siguientes se repasan, en primer lugar, aspectos relacionados con el salado de carne, en general, y en el Río de la Plata, en particular, durante la época, como los métodos utilizados y la relativa abundancia del insumo principal de la actividad. En segundo lugar, se analizará la demanda de carne salada proveniente del complejo portuario junto a los indicios disponibles respecto a la producción a pequeña escala a partir de la circulación interna de mercancías. En tercer lugar, se indagará sobre los vaivenes de la exportación del tasajo y las implicaciones que tuvo el cambio de escala en la producción, como el abastecimiento de los insumos necesarios, el surgimiento de establecimientos especializados y demás. Por último, se reflexionará sobre las características que tuvieron los saladeros en el siglo XVIII, para replantear así algunos tópicos que tienen su origen en descripciones de observadores que recorrieron la región durante la segunda mitad del siglo XIX. 


\section{El salado de carne}

Desde tiempos inmemoriales las sociedades han buscado distintas formas de conservar los alimentos. Extender la vida útil de un bien perecedero es fundamental en la administración de recursos que suelen ser escasos. Es más, en lugares donde las inclemencias del tiempo reducían las posibilidades de acceso a productos comestibles durante buena parte del año, la supervivencia misma de la población podía depender de esa preservación. En general, los métodos utilizados para la conservación se relacionan con someter el alimento a un proceso de deshidratación. La desecación puede producirse, simplemente, por la exposición al sol y al aire. Sin embargo, esto solo puede hacerse en climas muy secos, en la mayor parte de los casos la humedad impide que la acción de esos agentes sea suficiente y es necesario adicionar un elemento externo para lograr el efecto deseado. La sal es ideal para esto, ya que ayuda a extraer el agua de las células e inhibe, de esa manera, el crecimiento bacteriano. La carne es un alimento que sufre una rápida descomposición. Al sacrificar un animal, en especial cuando se trata de ganado mayor, la cantidad disponible supera generalmente las necesidades inmediatas de consumo. En consecuencia, es lógico que desde temprano y de forma muy extendida hayan surgido distintos métodos para su conservación, varios de los cuales llegaron al Río de la Plata al compás de las corrientes migratorias.

Así, se pueden observar menciones al charque ${ }^{1}$, el tasajo, la cecina y la carne salada en salmuera. La diferencia entre los tres primeros no siempre era clara y no necesariamente implicaban un método diferente de elaboración. Los particulares en sus declaraciones, o los funcionarios de la Real Hacienda, podían llegar a confundirlos. Sin embargo, en los libros de alcabala se diferencia entre distintos tipos de carne salada dentro de un mismo lote de mercancías, por lo que es probable que designen diferentes calidades y/o formas del producto. Charque y tasajo ${ }^{2}$ pueden haber sido sinónimos, salvo por el denominado charque dulce que no tenía sal y solamente estaba secado al sol. Giberti (1986, p. 26) sostiene que la cecina era charque envuelto en grasa y envasado en barricas. Aunque parece poco probable que la carne haya sido cubierta de grasa, ya que una de las alteraciones más comunes de la carne salada es, justamente, la oxidación de las grasas ${ }^{3}$. De todas maneras, el término posiblemente designaba un producto más refinado que el tasajo y más acorde al paladar europeo.

El método de elaboración básico de las carnes saladas consistía en cortar la carne en lonjas y ponerla por un breve tiempo en salmuera ${ }^{4}$, luego se escurría y, finalmente, se

\footnotetext{
1 Charque o charqui deriva del vocablo quechua ch'arki que tiene dos acepciones. Por un lado, significa "cecina, chalona, carne salada y seca" y, por el otro, se usa familiarmente para designar a una "persona delgada de carnes enjutas" (Diccionario quechua español quechua, 2005, p. 39), presumiblemente en alusión a la forma en tiras delgadas en la que es habitual encontrar la carne secada al sol.

2 Por ejemplo, en el libro de alcabalas de Montevideo de 1787, en el asiento del primero de abril aparece que Juan de Castilla le vendió a Simón Cucullu 25 quintales de carne salada y 25 quintales de cecina y el 6 de junio del mismo año quedó asentado que Pedro Díaz le vendió a Pedro Escardo 100 quintales de tasajo y 53 de carne salada (Biangardi, 2015, p. 114).

3 Este "enrranciamiento" y las fermentaciones superficiales constituyen las alteraciones más comunes del tasajo (Seoane, 1928, p. 193).

4 Esa parte del proceso se usa para acelerar la penetración de la sal, pero no es estrictamente necesario.
} 
Biangardi. Más allá del saladero. Una mirada sobre la producción de carne salada en el Río de la Plata del Siglo XVIII.

dejaba secar en pilas entre capas de sal por un plazo que podía variar entre cuarenta y cincuenta días $^{5}$ (Gilberti, 1986, p. 91). Por último, existía otro producto que consistía en carne que se conservaba en salmuera y que, por razones obvias, era más fácil de distinguir de los otros tipos y requería el envasado en barriles. Al parecer también estaba identificada como un alimento de mejor calidad y era preferido para el abasto de los navíos.

En las praderas rioplatenses la carne era abundante y barata y, aunque el consumo per cápita era elevado ${ }^{6}$, por las exportaciones de cueros se sabe que las cabezas de ganado sacrificadas superaban ampliamente las necesidades de consumo de la población ${ }^{7}$. Sin embargo, la producción de carne salada se mantuvo dentro de una escala reducida, al menos hasta las décadas finales del siglo XVIII. Esto induce a pensar en un gran desperdicio de carne. De hecho, esa era la impresión de varios de los observadores contemporáneos ${ }^{8} \mathrm{y}$, desde entonces, se transformó en un lugar común. No obstante, es necesario matizar un poco esta idea. La cuestión no consiste en si la carne se dejaba tirada para que se pudra o sirva de alimento a los perros cimarrones, sino si ese subproducto que se descartaba tenía algún valor.

Para que la carne de un animal sea comestible, la matanza debe hacerse de una cierta manera y el consumo tiene que producirse dentro de un rango de tiempo determinado. En primer lugar, para que la carne esté en condiciones de consumirse, el animal debe estar descansado al momento de su muerte. El ejercicio aeróbico genera que se consuman las reservas de oxígeno en los músculos. Si el ganado se mata después del mismo, se produce un proceso por el que la carne se endurece, se oscurece y se seca? Por eso en los establecimientos productivos se agrupaba a las vacas en corrales antes de la matanza. Pero no todas las cabezas de ganado eran sacrificadas en los mataderos. En las estancias más alejadas las condiciones eran muy distintas.

5 El secado de la carne depende de muchos factores que no se pueden controlar (como el clima) por lo que el tiempo de producción no es exacto. Se requiere experiencia para controlar el ritmo de secado y saber cuándo la carne está lista. De lo contrario, el producto final puede ser defectuoso. Por un lado, el secado no debe ser muy rápido porque la carne puede tomar un color oscuro, ponerse dura y la grasa tener un sabor desagradable; aunque, por otro lado, si el proceso es demasiado lento el producto puede conservar demasiada humedad y quedar expuesto a los hongos y bacterias (Seoane, 1928, p. 177).

6 Garavaglia (1999, p. 243) estimó que el consumo anual de carne vacuna por persona en Buenos Aires era de 193 kilos, lo que duplicaba el consumo europeo de todo tipo de carnes.

7 Para un panorama completo de la exportación de cueros desde el Río de la Plata durante todo el siglo XVIII y la primera mitad del siglo XIX, véase: Jumar (2016), Camarda (2016) y Rosal y Schmit (2004).

8 Es probable que algunos de los informes que destacaban el desperdicio de carne hayan estado influidos por el contraste que generaba en esos observadores el recuerdo de un contexto de escasez de carne (al menos en comparación a la abundancia que existía en las praderas rioplatenses) en sus lugares de origen, la mayor parte situados en la península ibérica. Sobre el peso que pueden tener esas ideas previas en los relatos de los viajeros, véase el análisis que hacen Patricio Fontana y Claudia Fontán (2009) de las representaciones de los mataderos rioplatenses del siglo XIX.

9 Los estudios actuales sobre los defectos de la carne plantean que cualquier situación de stress previa a la matanza tiene efectos sobre la calidad del producto. Entre las causas del dark firm dry (DFD) están: el traslado a larga distancia, la privación de agua y comida durante horas y el amontonamiento en los animales (Adzitey y Nurul, 2011, p. 12). 
Además, una proporción importante de los cueros que se exportaban se generaban a partir de las vaquerías corambreras. Éstas, además de hacerse en lugares alejados de los principales mercados consumidores, eran expediciones de caza en las cuales el ganado era alcanzado al trote y se le cortaba el tendón con el desjarretador para que caiga, con lo cual, salvo por las lenguas, la carne de esos animales difícilmente se podría haber aprovechado ${ }^{10}$. En segundo lugar, aunque el animal esté descansado, los músculos que componen la res se van a contraer después de un determinado tiempo, lo que se denomina rigor mortis, por lo que la carne debe consumirse de manera inmediata o luego de un proceso de maduración. La tecnología de la época obligaba a consumirla en el momento, con lo que el ganado debía ser trasladado hasta el mercado consumidor y, luego, debía descansar y recuperar peso antes de la matanza. De ahí la importancia de los mataderos situados en las ciudades o en zonas cercanas.

Por otro lado, hay que tener en cuenta que el ganado vacuno criollo era muy diferente al actual. Antes del refinamiento por cruces genéticos que se dio a fines del siglo XIX, los novillos de tres años apenas rondaban los 300 kilos, el cuero era más grueso y tenían una proporción de grasa reducida. Es decir, el rendimiento por animal era considerablemente menor. Por último, hay que considerar que el precio de la carne era bajo y, en consecuencia, no siempre era redituable trasladar el ganado hasta las ciudades portuarias. El mercado consumidor de carne fresca era reducido, debido al tamaño de la población, con lo cual, si no existía una demanda externa considerable, que en las condiciones de la época solamente podía ser de carne salada, el precio podía disminuir todavía más. Por ende, extraer el cuero, el sebo, la grasa y, quizás también, las astas dejando el resto del animal era la mejor opción, desde el punto de vista económico, al menos en la mayor parte de los casos. Para modificar esa ecuación era necesario que surgiera una demanda más amplia de carne.

El mercado de carne salada estaba compuesto principalmente de dos segmentos. Una demanda interna, que estaba orientada a satisfacer las necesidades de las tripulaciones de los navíos, especialmente como parte de los víveres para los viajes de retorno. El otro segmento tenía que ver, en cambio, con los exportadores que buscaban colocar el producto en los mercados esclavistas de Cuba y Brasil. Cada segmento se diferenciaba por la continuidad en el tiempo de esa demanda, por el tipo de bien que requería y por la magnitud de la misma, que repercutía en la escala de producción. La necesidad de abastecimiento de los navíos fue permanente durante todo el siglo y, aunque se incrementó considerablemente al final del período, se cubría con la producción de carne salada a pequeña escala en estancias y chacras que, al igual que otros víveres, llegaban a los puertos por medio de la circulación intrarregional. El caso de la exportación, en cambio, fue un fenómeno que surgió recién durante los años finales de la década de 1780 e implicó un cambio en la escala de producción que tuvo como consecuencia la aparición de establecimientos especializados localizados en la zona portuaria.

\footnotetext{
${ }^{10}$ Para un análisis de los efectos de las vaquerías sobre la carne del ganado y la excepción del caso de la lengua de los animales, véase: González Lebrero (2002, pp. 186-187).
} 
Biangardi. Más allá del saladero. Una mirada sobre la producción de carne salada en el Río de la Plata del Siglo XVIII.

\section{Producción de carne salada en estancias y chacras para satisfacer la demanda interna del complejo portuario}

La región Río de la Plata era un punto por donde pasaban amplios circuitos mercantiles que unían Europa con el Alto Perú y los puertos del Pacífico (Jumar, 2012). Ese tráfico comercial determinó la existencia de una considerable población flotante que demandaba alimentos y servicios, estimulando la actividad económica regional (González Lebrero, 2002; Jumar et al., 2006; Sandrín, 2016). Durante su estadía consumían carne fresca pero, debido a los problemas de conservación, se abastecían de carne salada para el viaje. El transporte terrestre de esclavos hacía el norte y el oeste podría haber generado también parte de esa demanda, sin embargo no lo hacía. Lo habitual era que el tropero se llevase ganado en pie, para no ocupar espacio en las carretas que podía destinarse a otras mercancías (González Lebrero, 2002, p. 157). Es decir, en este caso lo que se puede denominar como demanda interna, se encontraba reducida a las necesidades de abastecimiento de las tripulaciones de los navíos en sus viajes de retorno.

Partiendo de las raciones reglamentarias para las tripulaciones durante la navegación y, tomando los datos de Jumar (2000) y Camarda (2013) sobre embarcaciones que partieron desde el Río de la Plata, María Emilia Sandrín (2016) ha estimado la magnitud de la demanda de distintos víveres para abastecer a los navíos para su viaje de retorno. Dentro de esos alimentos se encuentran la carne salada y el tocino, tal como se encuentra presentado en la figura 1.

Figura 1. Estimación de quintales de carne salada y tocino necesarios para abastecer a las tripulaciones de embarcaciones ultramarinas durante el tornaviaje por quinquenios, 1703-1803

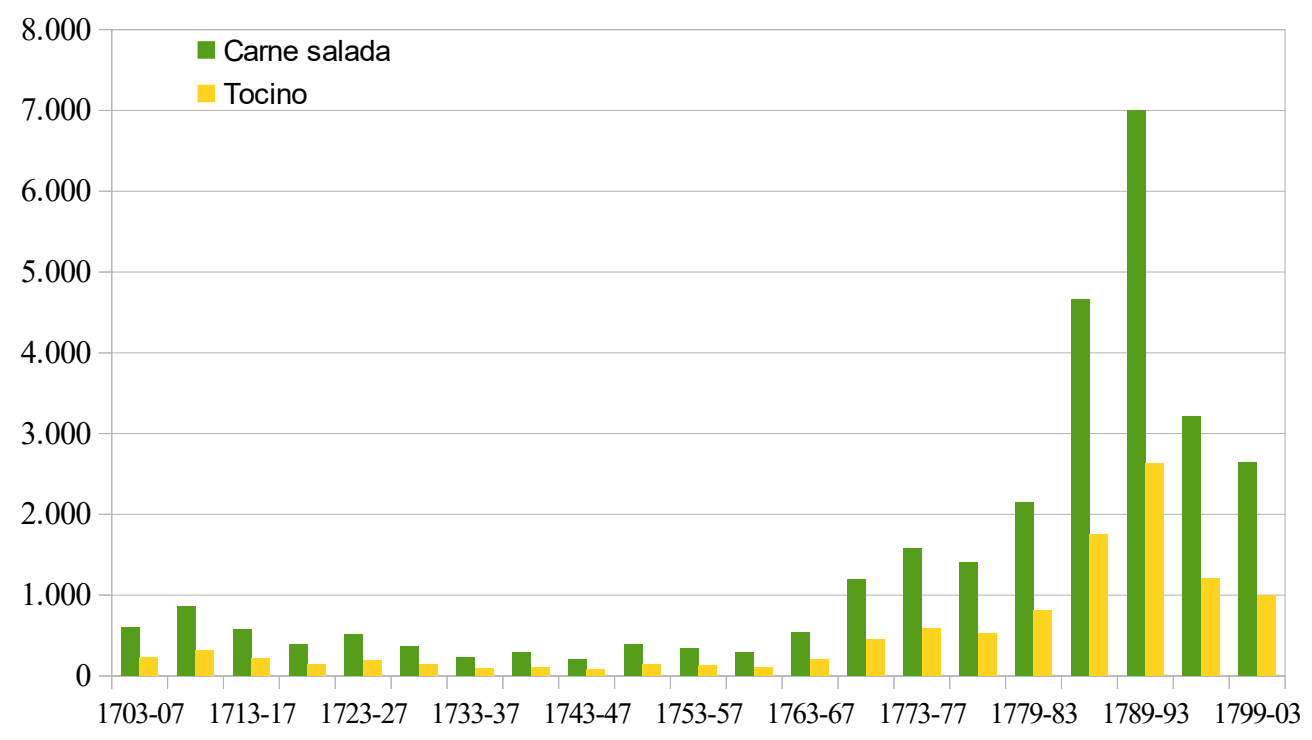

Fuente: Elaboración propia a partir de: Sandrín, 2016, pp. 38-40. 
El gráfico requiere dos aclaraciones. En primer lugar, los datos sobre embarcaciones salidas entre 1703 y 1778 solamente incluyen las que implicaban un vínculo comercial y tenían como destino algún puerto europeo, que eran la mayoría, pero la demanda debió ser mayor que la reflejada. En segundo lugar, se presentan los datos por quinquenios con la excepción del año 1778 que fue excepcional por la presencia de la flota que expulsó a los portugueses de Colonia del Sacramento, así lo presenta también la autora en su trabajo. Por ende, es probable que la curva ascendente de la demanda podría ser menos pronunciada, pero a pesar de esto, la tendencia se mantendría.

Más allá de estas cuestiones, se puede observar que esta demanda de carne salada y tocino para las tripulaciones fue permanente durante todo el siglo, pero se mantuvo dentro de niveles reducidos y solamente tuvo un crecimiento considerable en las últimas décadas. De todas maneras, incluso en el quinquenio que presenta la demanda más elevada, todavía se está ante una cantidad modesta como para tener un impacto significativo en la cría de ganado, especialmente en el caso de la carne vacuna.

Teniendo en cuenta un rendimiento de 1,25 quintales de carne salada por novillo $^{11}$, durante el quinquenio $1789-1793$ se necesitaron un promedio anual de 1.120 novillos para producir los quintales necesarios para abastecer a las tripulaciones, en el quinquenio anterior (1784-1788) se reduce a 746, en 1794-1798 a 514 y en 1799-1803 a 422, para mencionar los períodos en los que la demanda fue más importante. Puestas en contexto, esas cifras son bastante pequeñas. Por un lado, una sola estancia podía producir el procreo anual necesario para abastecer esta demanda. Por otro lado, teniendo en cuenta el consumo anual por persona ya mencionado, el mercado de carne fresca era muy superior. Por ejemplo, entre 1788 y 1792 el consumo promedio anual de la ciudad de Buenos Aires fue de 46.052 animales (Garavaglia, 199, p. 243) y el de Montevideo para la década de 1790 fue de 13.129 (Moraes, 2011, p. 199). Es decir, por si sola esta demanda interna no tenía un impacto significativo en el desempeño de la ganadería. Para que eso suceda va a ser necesario que se le sume la exportación.

En el caso del tocino la demanda también era modesta, aunque de todas maneras, es interesante para indagar en torno a la producción de ganado menor. Por un lado, hay que considerar que al abasto de las tripulaciones solamente se destinaba el tocino dejando el resto de la res porcina para el autoconsumo o para el mercado local, lo que podía hacerse en forma de carne fresca o, como se verá más adelante, también en la

\footnotetext{
${ }^{11}$ Un rendimiento aproximado ideal sería el resultado de la siguiente cuenta. Si un novillo tenía un peso promedio de 207 kilogramos de los cuales es necesario descontar un 35\% de desperdicio (Garavaglia, 1999, pp. 242-243) quedan 135 kilos de carne fresca. El proceso de salado y secado produce una merma del $45 \%$ (Seoane, 1928, p. 177) de manera que quedan 75 kilos de carne salada (1,6 quintales de 46 kilos). Sin embargo, teniendo en cuenta las pérdidas ocasionadas por alteraciones en el tasajo, como las ya mencionadas fermentaciones superficiales o la oxidación de las grasas, y dudando de la perfección de los procesos de elaboración del siglo XVIII se prefiere reducir ese rendimiento a 1,25 quintales. Además, esto está en consonancia con los cálculos que hace Moraes (2011, p. 204) a partir del stock ganadero y los objetivos de producción del primer saladero y con los rendimientos de los saladeros de Buenos Aires a fines del siglo XIX (entre 59 y 64 kilos, es decir entre 1,28 y 1,39 quintales) que mencionan Barsky y Djenderdjian (2003, p. 344).
} 
Biangardi. Más allá del saladero. Una mirada sobre la producción de carne salada en el Río de la Plata del Siglo XVIII.

elaboración de embutidos. Es decir, la presencia de este bien también es indicador de algunas de las características del autoconsumo de la población rural. Por otro lado, como constituía un sustituto de la carne salada dentro de la dieta de los marineros (unos días comían carne salada y otros, tocino) es de suponer que se trataba de tocino entreverado con magro o, dicho de otra manera, lo que en nuestra región denominamos actualmente panceta. ${ }^{12}$ Para asegurar su conservación durante el viaje lo más probable es que estuviera salado. Por ende, para tener una idea de la cantidad de animales sacrificados que representan esos quintales de tocino se puede plantear una media de dos piezas de entre 3 a 4 kilos de panceta salada por res porcina. En consecuencia, un quintal de tocino se podría formar a partir de 13 piezas de aproximadamente 3,5 kilos y, de esta manera, representaría 6,5 reses porcinas. En consecuencia, se puede estimar que en el momento de mayor demanda para el quinquenio 1789-1793, esos quintales de tocinos representan el consumo de 17.056 reses porcinas, 11.368 en 1784-1788, 7.832 en 17941798 y 6.441 en 1799-1803. Es decir, en el pico de la demanda apenas significó 3.411 cerdos sacrificados anualmente lo que es considerablemente poco para la población rioplatense, en especial cuando se lo compara con el consumo de carne fresca vacuna mencionado más arriba.

En consecuencia, si bien esta demanda podía ser un complemento en los ingresos de algunos productores y comercializadores de la campaña no tuvo, en cambio, un peso significativo sobre el conjunto de la economía agropecuaria de la época. Para eso fue necesario el impulso que generó la demanda destinada a la exportación de carne salada, que se concentró en el tasajo destinado a los mercados esclavistas del norte de Brasil y Cuba. Al tratarse de una producción situada en distintas estancias y chacras, y por ende, extendida a lo largo del espacio regional, es posible encontrar indicios de la misma a partir del estudio de la circulación de mercancías dentro de la región. Las guías de alcabala de Maldonado, ${ }^{13}$ por ejemplo, revelan que entre 1782 y 1786 se trasladaron 216 arrobas de charque en 15 viajes realizados por distintos individuos. Además, en otros dos viajes, los individuos llevaban "un poco" de charque, presumiblemente para consumo personal. Por su parte, José de Sosa en dos traslados realizados en 1786 llevaba entre sus mercancías una arroba de cecina en cada uno. En los años siguientes se registran varios envíos de los distintos tipos de carnes saladas y, especialmente, de lenguas saladas en pequeñas cantidades y de manera intermitente. En conjunto entre 1783 y 1806 se enviaron a Montevideo 4.412 arrobas de carnes saladas y 9.749 unidades de lenguas saladas. Además, entre los bienes transportados se observa la presencia de otra forma de conservar la carne, en este caso chorizos. La elaboración de estos embutidos es interesante porque, además de la utilización de sal y otros condimentos implicaba, también, el aprovechamiento de las tripas del ganado. No es posible saber de qué tipo de carne estaban hechos los chorizos. Pero podría ser porcina o una mezcla de carnes de distintos tipos de ganado. Por el problema de su conservación, se presume que se

\footnotetext{
${ }^{12}$ Sin dudas esta denominación actual tiene que ver con la influencia que tuvo la inmigración italiana a fines del siglo XIX y principios del XX, de manera que para la época que estamos estudiando lo mejor es conservar el término tocino para hacer referencia a ese bien.

${ }^{13}$ AGN Libros auxiliares de alcabala de guías en Sala XIII, Maldonado: Cajas de 3288 a 3312.
} 
trataban de chorizos secos, que se diferencian en su elaboración solamente por el uso de una mayor proporción de sal y el secado posterior. Entre los años 1782 y 1805 el envío de chorizos aparece en 37 guías de salida de Maldonado. Es difícil determinar la cantidad que transportaban porque no existía una medida unificada. En algunos casos se lo medía en varas ${ }^{14} \mathrm{y}$, a veces por docenas, aunque sin indicar el tamaño. ${ }^{15}$ Sin embargo, en su mayor parte se lo identificaba por el valor, es decir: tantos pesos de chorizos. ${ }^{16} \mathrm{En}$ la mayor parte de los casos, estos envíos eran parte de las modestas cargas de pulperos y productores rurales que transportaban la carne salada junto a otros bienes agropecuarios para venderlos en el mercado montevideano.

\section{Producción de carne salada destinada a la exportación}

Aunque existen indicios de exportaciones de carne salada realizados desde la Colonia del Sacramento en los momentos de ocupación portuguesa (Jumar, 2000), se puede decir que, a diferencia del segmento considerado anteriormente, la exportación de carne salada no tuvo una presencia continuada durante todo el siglo XVIII, sino que más bien fue un fenómeno que tiene sus comienzos a fines de la década de 1780 y se dio principalmente en la última década del siglo y la primera del siglo XIX. Durante esos años la producción de carne salada tuvo lugar en la costa norte del Río de la Plata, en especial su localización se concentró en las inmediaciones de Montevideo, y solamente va a surgir en la otra orilla durante la segunda década del siglo XIX cuando las vicisitudes de la guerra impidan el normal funcionamiento de las actividades económicas en la campaña montevideana.

La figura 2, elaborada a partir de las cifras que brindan Montoya (1984, p. 301) para 1787-1789 y Bentancur (1997, pp. 54-56) para los años 1793-1799 y 1802-1806, es indicativa del crecimiento que tuvieron las exportaciones de carne salada durante esos años. La cantidad de quintales anuales de carne salada producida anualmente en este segmento es incomparablemente superior al anteriormente analizado. El crecimiento de las cantidades exportadas fue muy importante, pasando de un nivel de 40.000 quintales anuales en la década de 1790 (con un pico de casi 80.000 en 1796) a superar los 120.000 en el bienio 1802-1803. Esa rápida expansión invita a reflexionar sobre distintos aspectos que la hicieron posible en esos años y las dificultades que encontró este segmento de la economía regional para mantener en el tiempo esos niveles actividad.

En primer lugar, el impacto sobre la ganadería, especialmente la del área de Montevideo donde se localizaron la mayor parte de los establecimientos, fue significativa. Siguiendo el rendimiento mencionado más arriba, la producción de carne salada llegó a requerir un máximo de 107.124 novillos en 1803 y 100.292 en 1802. Sin duda estos fueron años excepcionales, pero todas las cifras presentadas en el gráfico 2 son importantes si se las compara con el consumo del abasto de Montevideo que, de acuerdo a Moraes (2011, p. 199), se situaba en las 13.129 cabezas de ganado consumidas

\footnotetext{
${ }^{14}$ Por ejemplo, el 7 de agosto de 1797 Blas Vidal envío a Montevideo 40 varas de chorizo.

${ }^{15}$ Por ejemplo, el 5 de abril de 1783 Antonio Chalar trasladó a Montevideo 3 docenas de chorizos.

${ }^{16}$ Por ejemplo, el 25 de noviembre de 1786 Juan Pascual Pla mandó a Montevideo 8 pesos de chorizos.
} 
Biangardi. Más allá del saladero. Una mirada sobre la producción de carne salada en el Río de la Plata del Siglo XVIII.

como promedio anual en la década de 1790 y las 23.047 en la primera década del siglo XIX, aunque el autoconsumo era significativo y, por ende, el consumo total privado era bastante superior. Según la autora (Moraes, 2011, pp. 204-205) la demanda del segmento productor de carne salada ${ }^{17}$ sería equivalente a ese consumo total de carne fresca, con lo cual la demanda de novillos se duplicó con las lógicas consecuencias que esto tuvo para la ganadería montevideana.

Figura 2. Exportaciones anuales de carne salada desde Río de la Plata en quintales y tendencia exponencial, 1787-1806

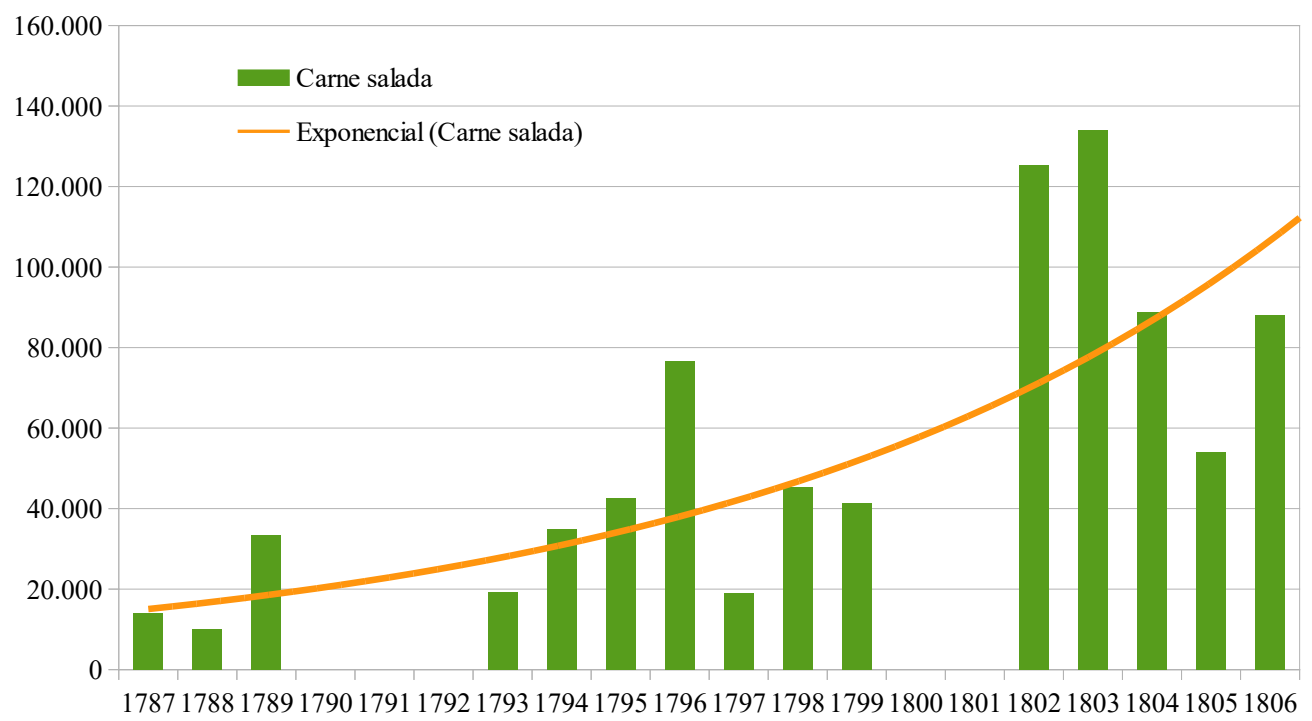

Fuente: Elaboración propia a partir de: Bentancur (1997, pp. 54-56) y Montoya (1984, p. 301).

Ahora bien, es de suponer que el éxito en abastecer ese crecimiento tan rápido de la demanda de cabezas de ganado se debió a que consistía en un bien que ya estaba disponible. Hacen falta tres años para que un novillo pueda destinarse al mercado de carne, de manera que los rápidos cambios en la demanda de un año a otro no pueden ser satisfechos, al menos que el stock ganadero ya exista. Para la coyuntura de 18021803 la disponibilidad de ganado se debió a que, en los años anteriores, la reducción del tráfico marítimo por la guerra permitió la expansión del stock ganadero. En este sentido, también sería necesario replantear la noción de sobrematanza de animales a las que hacen referencia los informes de funcionarios preocupados por el abastecimiento de carne fresca de la población, que habitualmente eran acompañadas por la prohibición de matar vacas para no afectar la reproducción, pero que no tiene sentido desde el punto de vista de la lógica económica de los productores que buscaban maximizar las

\footnotetext{
${ }^{17}$ Moraes (2011, pp. 204-205) estima esa demanda en 44.000 cabezas anuales entre $1787-1796$ y cerca de 60.000 entre $1798-1808$.
} 
ganancias que permitía el contexto de apertura del mercado, sabiendo que luego se puede recomponer el stock cuando el mismo se vuelva a cerrar. ${ }^{18}$

Una cuestión diferente se plantea con respecto al otro insumo necesario: la sal. El abastecimiento de sal es, junto al problema de los mercados consumidores que se considerará más adelante, uno de los inconvenientes más importantes que tenía esta producción. De hecho, es probable que algunos intentos de salazón hayan fracasado por escasez de sal de buena calidad a precios bajos, tal como consideraba Giberti (1986, p. 56).

Un análisis de los precios de la sal en Montevideo según su origen permite sacar varias conclusiones al respecto. En Montevideo se distinguía la sal de acuerdo con cuatro procedencias distintas. Como se puede observar en el gráfico 3, la sal que llegaba de las salinas a través de Buenos Aires se encontraba disponible de manera permanente pero su precio era elevado, al menos en relación con la proveniente de otros lugares, lo que parece ser la consecuencia de los costos relacionados a las expediciones a las salinas. ${ }^{19}$ Por otro lado, la sal procedente de Córdoba, si bien tenía un nivel de precios menor a la de las salinas y similar al de la importada desde España, solamente se encuentra presente en los primeros años del período analizado. Por ende, la figura 3 sugiere que la producción saladera pudo haber dependido del abastecimiento de sal vía marítima, ya sea desde Carmen de Patagones o desde la península Ibérica. Esto es coincidente, además, con el descenso del nivel de precios cuando el tráfico marítimo era más intenso y con el aumento del precio en los años de conflictos bélicos. Además, al tratarse de la producción de un bien destinado a la exportación, los momentos de mayor disponibilidad de sal eran también los de mayor demanda de carne salada. Es decir, cuando había embarcaciones que, luego de descargar los productos importados, tenían espacio en las bodegas para la exportación de mercancías.

Las fluctuaciones del comercio ultramarino en ese contexto de crisis de la monarquía plantean la necesidad de analizar la injerencia del capital comercial en este segmento productivo y el problema que representan los mercados consumidores de esta mercancía en particular. La diferencia de escala implicó inconvenientes derivados de la necesidad de mano de obra, un adecuado abastecimiento de los dos insumos necesarios (carne y sal), espacio de almacenamiento y ciertas previsiones en cuanto a la colocación de los bienes que obligaron a un cambio con respecto a las prácticas de producción de carne salada a pequeña escala en las estancias y chacras, lo que llevó a la conformación de nuevos establecimientos productivos dedicados a la salazón. Varios comerciantes estuvieron relacionados con la instalación de estos saladeros, dándose incluso asociaciones entre algunos comerciantes y ganaderos que aseguraban

\footnotetext{
${ }^{18}$ Por supuesto, que esto era posible sobre todo para los estancieros que podían hacer frente a años con escasos ingresos, esperando una coyuntura mejor, mientras que los pequeños productores debían seguir vendiendo aún en las condiciones más desfavorables. Esta situación también perjudicó a los medianos productores que tampoco tenían la posibilidad de permitir el crecimiento del stock ganadero (ya sea por falta de espacio o por falta de capitales) y, como señaló Gelman (1998, pp. 110-111), eso tuvo como consecuencia un proceso de polarización de la estructura agraria entre grandes y pequeños productores a costa de los medianos.

${ }^{19}$ Sobre las expediciones a las salinas, véase: Taruselli (2006).
} 
Biangardi. Más allá del saladero. Una mirada sobre la producción de carne salada en el Río de la Plata del Siglo XVIII.

el adecuado aprovisionamiento de novillos. ${ }^{20}$ De todas maneras, también es necesario revisar las concepciones que se tienen sobre las características de los saladeros en esa época y su verdadero peso en la economía colonial ya que, como se verá en detalle más adelante, gran parte de esa imagen está influida por descripciones de los saladeros de la segunda mitad del siglo XIX.

Figura 3. Precio promedio anual de la cuartilla de sal, en reales, e acuerdo a su procedencia. Montevideo 1787-1806.

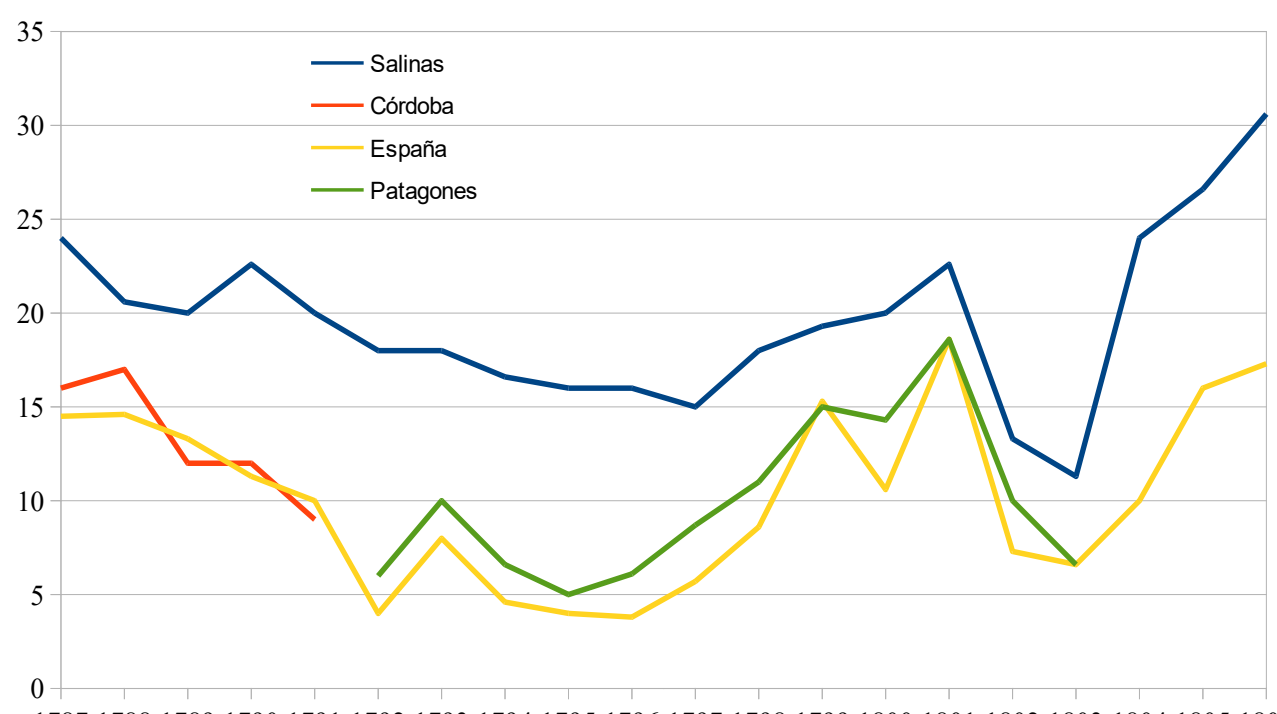

17871788178917901791179217931794179517961797179817991800180118021803180418051806

Fuente: Elaboración propia a partir de: Biangardi, 2015, pp. 240-242.

Por otro lado, la existencia de la producción en chacras y estancias y la presencia activa de los comerciantes permite pensar que en momentos de auge de la demanda se podría haber dado una especie de verlagsystem en el que los comerciantes abastecieran a los productores de sal y les encargasen una determinada cantidad de quintales de carne salada. ${ }^{21}$ Sin embargo, la baja densidad poblacional y las distancias hacen improbable que se haya implantado este sistema, más allá de que algún pulpero rural pueda recoger esa producción a pequeña escala para luego venderla en el mercado urbano. Lo más lógico, desde el punto de vista económico, era el transporte del ganado hasta una zona portuaria donde la producción se podía embarcar con costos menores. ${ }^{22}$ Esto explica la

${ }^{20}$ Un ejemplo de esta situación se da en el contrato suscrito en 1795 entre Mila de la Roca y Francisco Antonio Maciel que incluía la provisión de novillos por parte de las estancias de Juan Francisco García (Bentancur, 1998, pp. 52-53).

${ }^{21}$ Sobre el verlagsystem, véase: Kriedte, Medick y Schlumbohm, 1986.

${ }^{22}$ Las teorías sobre localización de las actividades económicas, y para este caso en particular la teoría de la localización industrial de Alfred Weber, hacen hincapié en la influencia de los costos de transporte. Desde este punto de vista los puertos, que son lugares donde las mercancías pasan de un tipo de transporte a 
localización de los saladeros en estancias con puertos naturales, como el caso de Colla, ${ }^{23}$ o en ciudades portuarias como Maldonado y sobre todo, Montevideo. La presencia de los navíos, la disponibilidad de sal que llegaba en éstos, la vitalidad de la ganadería del área y el acceso a mano de obra (tanto libre como esclavizada) explican que la mayor parte de los establecimientos productores de carnes saladas de la época se instalaran en Montevideo. ${ }^{24}$

En cuanto a los mercados consumidores, debido a las características de la mercancía éstos estaban limitados a las economías de plantación esclavistas. El principal mercado para el tasajo rioplatense era Cuba, aunque también se hicieron envíos importantes al norte de Brasil. Estos mercados estaban fuera de los circuitos mercantiles habituales, de las mercancías exportadas desde el Río de la Plata (plata, cueros, sebo), que conectaban la región con el mercado europeo. En este sentido, la exportación de la carne salada rioplatense dentro del comercio legal español es, en parte, producto de las medidas liberalizadoras del comercio emprendidas por la Corona. Primero con el Reglamento de comercio libre de 1778 pero, sobre todo, con la autorización del comercio con colonias extranjeras desde 1795 que legalizó el comercio con Brasil y con países neutrales desde 1797.

De acuerdo a los datos proporcionados por Arturo Bentancur (1997, p. 52-55) las exportaciones a la Habana no dejaron de crecer en los períodos que la guerra no interrumpía el tráfico marítimo. Entre 1792 y 1796 se enviaron 157.125 quintales de carnes saladas en 41 embarcaciones y en 1802-1806 salieron 97 embarcaciones que transportaron 382.471 quintales. En ese último período, las medidas liberalizadoras del comercio por parte de la corona permitieron la apertura de nuevos mercados exportándose otros 149.246 quintales a colonias y países extranjeros, especialmente a Brasil a donde fueron a parar el $71 \%$ de esos embarques.

En estos mercados consumidores, la carne salada rioplatense competía con la producida en otras zonas como Río Grande y Caracas. Este es un problema para el que no se cuenta con información suficiente y que sería interesante dilucidar. Para eso es necesario conocer varias cuestiones: cuál era el lugar que ocupaba la carne salada en la dieta de los esclavos, realizar estimaciones de esa demanda, a qué precios se vendía esta mercancía en esos mercados y en qué medida variaba el mismo según el origen del bien. Sería interesante, también, poder hacer comparaciones sobre las condiciones de producción, transporte y comercialización de cada una de las regiones que producían carnes saladas. Dilucidar todas estas cuestiones es fundamental para tener un panorama completo del problema.

otro, son espacios privilegiados para la localización de actividades que transformen las materias primas en mercancías con un mayor valor agregado, ya sean manufactureras o industriales.

${ }^{23}$ En esa estancia estaba instalado el saladero de Francisco Antonio Medina estudiado por Montoya (1984) y por Bentancur (1987).

${ }^{24}$ La presencia de estos establecimientos lleva a Bentancur (1998) a afirmar que en los años 1790 se conformó en las afueras de Montevideo un "cinturón industrial". Lo que en una primera impresión parece un poco exagerado, especialmente por la caracterización del saladero como "industria" (punto que se discutirá más adelante) pero que es ilustrativo de esa localización preferencial. 
Biangardi. Más allá del saladero. Una mirada sobre la producción de carne salada en el Río de la Plata del Siglo XVIII.

De todas maneras, es posible afirmar que la producción de carnes saladas tuvo una cierta importancia dentro de la estructura productiva rioplatense, aunque su expansión más significativa se va a dar recién en la segunda mitad del siglo XIX. La composición de las exportaciones refleja esta situación al mostrar un crecimiento de la participación del tasajo y otros derivados de la explotación del ganado en el total de las mismas. En este sentido, Miguel Ángel Rosal y Roberto Schmit (2004, p. 166) muestran que la contribución de los cueros vacunos en el valor total de los bienes exportados disminuyó desde el $95 \%$ en el período $1779-1783$, pasando a $87 \%$ en 1792-1796 y llegando a $67 \%$ para la década de 1820 .

La comparación con Río Grande es ilustrativa de las diferencias con esa región, al mismo tiempo que refrenda esa evolución temporal. En los años finales del siglo XVIII la producción de tasajo de Río Grande era equivalente a la montevideana, situándose en un poco más de 50.000 quintales en 1790 . En cambio, a principios del siglo XIX las exportaciones de carne salada van a tener una participación muy importante en las exportaciones riograndenses: representando $44 \%$ del valor de las exportaciones en 1808 y llegando a 63,2\% en 1819 (Osorio, 2007, p. 195). Es probable que parte de esa expansión tenga que ver con que en esos momentos la producción rioplatense había decaído, debido a la desaparición de los establecimientos montevideanos y a que apenas se estaban instalando los primeros saladeros en las cercanías de Buenos Aires. De acuerdo a las cifras brindadas por Montoya (1971, p. 152) las exportaciones de Buenos Aires de la década de 1820 se situaban casi al mismo nivel de las de Montevideo en los años 1802-1803. Recién a partir de mediados de siglo se puede considerar que la producción del Río de la Plata superó a la riograndense cuando las exportaciones de Buenos Aires y de Montevideo sean superiores, y en conjunto más del doble, que las de Río Grande (Vargas, 2014, p. 557).

\section{El saladero del siglo XVIII}

Es necesario, entonces, indagar sobre los primeros saladeros que surgieron a fines del siglo XVIII para plantear algunas cuestiones. Por un lado, reflexionar acerca de las características que tenían esos establecimientos productivos en esa época y diferenciarlos de los que existieron más de medio siglo más tarde. Por otro lado, considerar cuál fue su peso en el conjunto de la economía regional.

En primer lugar, hay que tener en cuenta que, tal como plantean Barsky y Djenderedjian (2003, p. 147), el saladero no era una industria sino una manufactura. ${ }^{25}$ Simplemente concentró procesos de elaboración que, como se observó más arriba, ya se hacían en distintos establecimientos rurales. En consecuencia, no implicó ningún adelanto tecnológico, éstos se darán recién en el siglo siguiente, ${ }^{26}$ pero si cambios

\footnotetext{
${ }^{25}$ Sala de Tourón, de la Torre y Rodríguez (1967, p. 54) consideran, incluso, que el saladero era una semimanufactura porque "de la manufactura tiene la concentración en el establecimiento de un número relativamente importante de trabajadores y una división primaria del trabajo, pero simultáneamente posee un nivel técnico muy bajo y utiliza mano de obra esclava".

${ }^{26}$ En este sentido, fueron especialmente importante la incorporación del arsénico para el tratamiento de los
} 
importantes en la organización y la escala de la producción. Esto, sin duda, es importante porque sin esa organización y concentración de actividades no habría sido posible el cambio de escala, que ya se observó al analizar la evolución de las exportaciones.

La mayor parte de las descripciones disponibles de los saladeros datan de la segunda mitad del siglo XIX, cuando la producción saladeril estaba en su momento de esplendor ${ }^{27}$. En general, se plantea que esos establecimientos productivos requerían de una importante inversión de capital. Sin embargo, éste también es un tópico que se puede, al menos, revisar para el caso del siglo XVIII. Si se parte de la realidad de que la producción de carne salada se trataba de una práctica extendida en las estancias, de la existencia de varios mataderos, de la no incorporación de tecnología y del bajo valor de la tierra en esos momentos, no parece que un saladero requiriera una inversión considerable. En este sentido, es probable que la única diferencia que presentase un saladero de fines del siglo XVIII respecto a un matadero, que ya se dedicaba extraer el cuero, el sebo y la grasa y en la medida de lo posible también carne fresca para vender en el mercado urbano (si las distancias con respecto al mismo se lo permitían), consistía en que debía tener un espacio de almacenamiento más amplio del que ya tenía (para proteger los cueros, la grasa y el sebo de la lluvia y el sol), para ahora tener lugar para la sal y el tasajo. ${ }^{28} \mathrm{La}$ ampliación podía ser importante, pero es de suponer que no sería más que un rancho de adobe y techo de paja con un costo incomparablemente menor que los depósitos de la casa de un comerciante en la ciudad. Durante la segunda mitad del siglo XIX cuando la tierra tenga un precio considerablemente mayor, representando un porcentaje importante del valor de los establecimientos rurales, y los saladeros utilicen vapor para extraer la grasa en tinas de cobre, la situación se presenta de una manera más cercana a las descripciones disponibles.

Una hipótesis aplicable al área de Montevideo, a fines del siglo XVIII, consiste en que la existencia previa de mataderos fue lo que permitió cambiar rápidamente la escala de producción de carne salada, ampliando las actividades que se realizaban en esos establecimientos con una inversión mínima. En otro trabajo (Biangardi, 2017) he mostrado la existencia de esos mataderos, a partir de la procedencia de los cueros, sebo y grasa que llegaban a Montevideo. De todas maneras, aún en los casos en que un saladero se tuviera que instalar de cero, la inversión era considerablemente menor en comparación con la necesaria durante la segunda mitad del siglo XIX. Es, justamente, esa reducida necesidad de capital la que permitía a los agentes económicos la flexibilidad necesaria para hacer frente a las rápidas y constantes fluctuaciones de la demanda externa. Es la misma situación que se planteó al discutir la noción de "sobrematanza" del ganado. La forma de maximizar las ganancias del sector exportador, en esas condiciones, estaba dada por la posibilidad de incrementar la producción rápidamente en las coyunturas favorables con la menor inversión posible en capital fijo para reducir los gastos, y

cueros y del vapor para la extracción de grasas.

${ }^{27}$ Especialmente se destacan por la difusión y el uso que tienen en la historiografía las de Martín de Moussy (1860) y la de Carlos Lemée (1894).

${ }^{28}$ Esto es evidente, por ejemplo, en la descripción que hace Montoya (1984, p. 132-136) de la estancia y saladero de Francisco Medina en Rosario de Colla. 
Biangardi. Más allá del saladero. Una mirada sobre la producción de carne salada en el Río de la Plata del Siglo XVIII.

posibles pérdidas, que podían ser gravosos en los momentos en los que el comercio atlántico disminuía.

Lo adecuado, entonces, sería pensar el salado de carne como parte de las empresas agrarias, más allá de la escala, y no como una agroindustria, lo que para la época es realmente anacrónico. ${ }^{29}$ En este sentido, no escapa de la lógica que, como plantean Schmit y Djenderedjian (2010), predomina entre los empresarios rurales hasta 1850. Por ende, denominar "saladeros" a esos establecimientos productivos genera equívocos, ya que destaca solamente uno de los bienes que se producían en esos sitios, marginando al resto (cuero, sebo, grasa y astas) a un lugar secundario que no tenían. En consecuencia, es probable que la denominación "mataderos" sea más adecuada, ya que puede hacer referencia a ese tipo de establecimientos ya sea que salasen la carne, la vendiera fresca o la descartasen.

Por otro lado, teniendo en cuenta las exportaciones totales de la región se puede plantear que los historiadores exageraron la importancia de los saladeros. La exportación de tasajo nunca ocupó un lugar preponderante dentro de las mismas, como el caso de los cueros o la lana. De hecho, durante la segunda mitad del siglo XIX su participación en el total de las exportaciones argentinas, de acuerdo al valor, se situaba apenas entre el 3 y el $6 \%$ (Barsky y Djenderjian, 2003, p. 344). Es decir, más allá de cierta importancia en momentos puntuales, especialmente en sus consecuencias sobre la actividad ganadera, o del hecho de haber sido una oportunidad de ganancias significativas para un grupo determinado, el salado de carne para la exportación no representó un papel tan significativo dentro de la economía agropecuaria regional.

\section{Consideraciones finales}

En síntesis, a lo largo del texto se indagó sobre distintos aspectos que presentaba la producción de carne salada en la región Río de la Plata durante el siglo XVIII y los primeros años del XIX. Se hizo hincapié, en primer lugar, en estudiar la demanda de esta mercancía ya que, como la carne era abundante y el procedimiento para salarla relativamente sencillo, solamente era necesario contar con el incentivo necesario para producirla. En segundo lugar, se plantearon algunos problemas concernientes a la provisión de insumos, básicamente sal, y la naturaleza de los establecimientos productivos.

Existía, por un lado, una demanda de carne salada proveniente de las necesidades de abastecimiento de los navíos para sus viajes de retorno. Esta fue permanente durante todo el siglo XVIII y se incrementó en los últimos años de dicho período, con el aumento de la cantidad de embarcaciones que arribaban al Río de la Plata. Sin embargo, la magnitud de la misma fue bastante modesta, aún en los picos más altos. De esta manera, se puede afirmar que alcanzaba con la producción a pequeña escala de carne salada en chacras y estancias para abastecerla y que, por ende, no tuvo un impacto significativo sobre la ganadería.

\footnotetext{
${ }^{29}$ Por ejemplo, Giberti (1984, p. 92) consideraba que se trataba de la "aparición del saladero como entidad industrial independiente de la estancia...".
} 
A fines de la década de 1780 surgió un nuevo tipo de demanda proveniente de la exportación de carne salada. El acelerado crecimiento de los embarques en los años posteriores ocasionó un cambio en la escala, que generó la instalación de establecimientos productivos especializados en la producción de tasajo; localizados, especialmente, en los alrededores de Montevideo. Esta corriente exportadora fue, en parte, consecuencia de las medidas liberalizadoras del comercio que emprendió la monarquía, ya que sus mercados consumidores (las economías esclavistas de Cuba y el norte de Brasil) estaban fuera de los circuitos mercantiles habituales que conectaban la región con la península ibérica.

La producción de tasajo sufrió las fluctuaciones del comercio ultramarino. En los momentos de conflictos bélicos la disminución del tráfico implicaba dificultades, tanto en la posibilidad de embarcar la producción como en el aprovisionamiento adecuado de sal. Su influencia, por lo tanto, fue limitada tanto en el tiempo como espacialmente afectando solamente a la campaña montevideana. Recién durante la segunda década del siglo XIX se emprenderá el salado de carne en las cercanías de Buenos Aires, cuando la producción en los alrededores de Montevideo ya había desaparecido.

Finalmente, se plantearon algunas cuestiones con respecto a la naturaleza de los establecimientos productivos. Especialmente se revisaron algunos tópicos comunes que son producto de retrotraer al siglo XVIII características que son propias de los saladeros de la segunda mitad del siglo XIX. En primer lugar, los saladeros no constituían una industria sino más bien una manufactura que, simplemente, concentraba en un espacio único procesos que ya se hacían de manera extendida, sin incorporar ninguna tecnología. En segundo lugar, se discutió la noción de que estos establecimientos requerían una importante inversión de capital. El reducido precio de la tierra, la ausencia de tecnología y la escasa diferencia con las instalaciones de una estancia o de un matadero desmienten esa afirmación para los años finales del siglo XVIII. Ese bajo nivel de inversión brindaba la flexibilidad necesaria para hacer frente a las fluctuaciones del comercio ultramarino y es coherente con la lógica que imperó en las empresas rurales al menos hasta 1850. Por último, se puede argumentar que la denominación "saladero" es equívoca ya que hace hincapié solamente en uno de los bienes que se producían en esos establecimientos, en detrimento del resto (cueros, sebo, grasa, astas) que no eran menos importantes que la carne salada. Por ende, una mejor opción podría ser utilizar la denominación "mataderos" que hace referencia a la totalidad del procesamiento de las reses vacunas, más allá de lo que se hiciera con uno de los subproductos: la carne.

En consecuencia, es probable que la principal conclusión de este breve balance consista simplemente en la constatación de que el estudio de la producción y comercialización de la carne salada no debe separarse de las investigaciones que se ocupan del resto de los bienes pecuarios ya que, más allá de las diferencias en los circuitos mercantiles externos, responden a las mismas condiciones estructurales que dictaban la lógica económica de la producción agropecuaria. 
Biangardi. Más allá del saladero. Una mirada sobre la producción de carne salada en el Río de la Plata del Siglo XVIII.

\section{Referencias Bibliográficas}

Academia Mayor de la Lengua Quechua. (2005) Diccionario Quechua Español Quechua. Cusco. Adzitey, F. y Nurul, H. (2011) Pale soft exudative (PSE) and dark firm dry (DFD) meats: Cause and measures to reduce these incidence-A mini review. International Food Research Journal, $\mathrm{n}^{\circ} 18$.

Barsky, O. y Djenderedjian, J. (2003) Historia del capitalismo agrario pampeano. Tomo 1. La expansión ganadera hasta 1895. Buenos Aires: Siglo XXI.

Bentancur, A. A. (1987) Francisco de Medina: la empresa de la discordia. Montevideo: Arca. Bentancur, A. A. (1998) El puerto colonial de Montevideo. Tomo I. Guerras y apertura comercial: tres lustros de crecimiento económicos 1791-1806. Montevideo: Facultad de Humanidades y Ciencias de la Educación.

Biangardi, N. (2013) Una nueva área para la región. Poblamiento y crecimiento económico en Maldonado (1755-1814). Revista Uruguaya de Historia Económica, vol. 3, no 4.

Biangardi, N. (2015) Expansión territorial, producción ganadera y relaciones de poder en la región Río de la Plata. Montevideo y Maldonado a fines del siglo XVIII. Tesis de doctorado. Universidad Nacional de La Plata.

Biangardi, N. (2017) Un estudio de la circulación de bienes pecuarios en el Río de la Plata, Montevideo 1784-1797. História econômica \& história de empresas, vol. 20, $\mathrm{n}^{\circ} 1$.

Camarda, M. (2013) Circulación ultramarina de navíos del Complejo Portuario Rioplatense (1779-1806). Anuario del Instituto de Historia Argentina, $\mathrm{n}^{\circ} 13$.

Camarda, M. (2014) De comerciante exitoso a hacendado y revolucionario. La estrategia económica de fines del siglo XVIII en el complejo portuario rioplatense a partir de un actor: José Ramón Milá de la Roca.Naveg@mérica, n 12.

Camarda, M. (2016) El comercio ultramarino de cueros salidos por el complejo portuario rioplatense en la segunda mitad del siglo XVIII. Fronteras de la Historia, vol. 21.

Fontana, P. y Fontán, C. (2009) De paseo a la muerte. Imágenes del matadero en los viajeros al Plata y sus reescrituras en la literatura argentina. Montevideo: Coloquio Internacional Montevideana VI: "Los viajeros y el Río de la Plata: un siglo de escritura".

Garavaglia, J. C. (1999) Pastores y labradores de Buenos Aires. Una historia agraria de la campaña bonaerense 1700-1830. Buenos Aires: Ediciones de la Flor.

Gelman, J. (1998) Campesinos y estancieros. Una región del Río de la Plata a fines de la época colonial. Buenos Aires: Libros del Riel.

Giberti, H. (1986) Historia económica de la ganadería argentina. Buenos Aires: Hyspamerica.

González Lebrero, R. E. (2002) La pequeña aldea. Sociedad y economía en Buenos Aires (1580-1640). Buenos Aires: Biblos.

Jumar, F. (2000) Le comerce atlantique au Río de la Plata 1680-1778. Tesis de doctorado, École des Hautes Études en Sciences Sociales.

Jumar, F. (2012) La región Río de la Plata y su complejo portuario durante el Antiguo Régimen. En: Fradkin, R. (dir.). Historia de la provincia de Buenos Aires. Tomo 2. De la conquista a la crisis de 1820. Buenos Aires: Edhasa.

Jumar, F. (2006) El comercio ultramarino por el complejo portuario rioplatense y la economía regional, 1714-1778. Magallánica, vol. 3, nº 5. 
Jumar, F. (2006) El comercio ultramarino y la economía local en el complejo portuario rioplatense. Siglo XVIII. Anuario IEHS, no 21.

Kriedte, P., Medick, H. y Schlumbohm, J. (eds.). 1986. La industrialización antes de la industrialización. Barcelona: Crítica.

Lemée, C. (1984) La agricultura y la ganadería en la República Argentina. Origen y desarrollo. La Plata.

Montoya, A. J. (1971) La ganadería y la industria de salazón de carnes en el período 1810-1862. Buenos Aires: El Coloquio.

Montoya, A. J. (1984) Cómo evolucionó la ganadería en la época del virreinato. Buenos Aires: Plus Ultra.

Moraes, M. I. (2011) Las economías agrarias del litoral rioplatense en la segunda mitad del siglo XVIII. Paisajes y desempeño. Tesis de doctorado, Universidad Complutense de Madrid.

Moussy, M. De. (1860) Description géographique de la Confédéracion Argentine. París: Fimin Didot, 1860.

Osorio, H. (2007) O império português no sul da América: estancieros, lavradores e comerciantes. Porto Alegre: UFRGS.

Parcero Torre, C. (2005) La alimentación en Cuba en el siglo XVIII. Revista de Humanidades: Tecnológico de Monterrey, $\mathrm{n}^{\circ} 19$.

Rosal, M. A. y Schmit, R. (2004) Las exportaciones pecuarias bonaerenses y el espacio mercantil rioplatense (1768-1854). En: Fradkin, R. O. y Garavaglia, J. C. (ed.). En busca de un tiempo perdido. La economía de Buenos Aires en el país de la abundancia 1750-1865. Buenos Aires: Prometeo.

Sandrín, M. E. (2016) La demanda de bienes y servicios para la Corona y la navegación ultramarina en el complejo portuario rioplatense y la dinamización de la economía regional. 1680-1810. Tesis de doctorado, Universidad Nacional de La Plata.

Sala de Tourón, L., De La Torre, N. y Rodríguez, J. C. (1967) Estructura económicosocial de la colonia. Montevideo: Ediciones Pueblos Unidos.

Schmit, R. y Djenderedjian, J. (2010) Los límites de la gran empresa agraria en el nacimiento del capitalismo rioplatense. Una estancia entrerriana durante la primera mitad del siglo XIX. Anuario IEHS, ${ }^{\circ} 25$.

Seoane, P. (1928) La industria de la carne en el Uruguay. Montevideo, Castelnuovo \& Bescheri. Silva, H. A. El comercio entre España y el Río de la Plata. Madrid, Banco de España, Servicio de Estudios, Estudios de Historia Económica, n 26, 1993.

Taruselli, G. D. (2006) Las expediciones a salinas: caravanas en la pampa colonial. El abastecimiento de la sal a Buenos Aires (Siglos XVII y XVIII). Quinto sol, $\mathrm{n}^{\circ} 10$.

Vargas, J. M. (2014) Abastecendo plantations: A inserção do charque fabricado em Pelotas (RS) no comércio atlântico das carnes e a sua concorrência com os productores platinos (sêculo XIX). História (São Paulo), vol. 33, nº 2. 
